\title{
Missing IUCD strings: an analysis
}

\section{Upasana Verma ${ }^{1}$, Mamta Gupta ${ }^{2 *}$, Vandana Saini ${ }^{3}$}

\begin{abstract}
${ }^{1}$ Department of Obstetrics and Gynecology, UCMS and GuruTeg Bahadur Hospital, Delhi, India
${ }^{2}$ Department of Obstetrics and Gynecology, GL Maternity Hospital, Delhi, India

${ }^{3}$ Department of Obstetrics and Gynecology, Hindu Rao Hospital, Delhi, India
\end{abstract}

Received: 22 July 2018

Accepted: 28 August 2018

\section{*Correspondence:}

Dr. Mamta Gupta,

E-mail: write2mamta55@gmail.com

Copyright: $\odot$ the author(s), publisher and licensee Medip Academy. This is an open-access article distributed under the terms of the Creative Commons Attribution Non-Commercial License, which permits unrestricted non-commercial use, distribution, and reproduction in any medium, provided the original work is properly cited.

\begin{abstract}
Background: Missing IUCD strings, i.e. IUCD strings that are not visible at the external cervical os, are a commonly encountered problem and needs to be analysed.

Methods: IUCD users coming for routine checkup (follow-up / renewal / removal) or with any complaints related to IUCD or gynecological complaints or referred from other health center and found to be having missing threads were included in the study. Complaints by woman, obstetric history, details of IUCD insertion, USG imaging reports were recorded. Removal of IUCD was done if indicated or if the woman desired so, by simple OPD procedure and if required in operation theatre.

Results: Out of 324 IUCD users who were examined in OPD, missing IUCD threads were found in 69. About half of them were asymptomatic. AUB was the commonest symptom. $82.6 \%$ women had IUCD in situ on USG. Displacement was seen in $10.14 \%$, embedment in $4.35 \%$. Expulsion was seen in $4.35 \%$ women. Removal was done in only 29 women. Removal was done by simple OPD procedure in 24 women, as minor OT procedure in 3 . Only 1 required hysteroscopic removal. Commonest cause of missing threads was found to be broken, detached or severed strings.

Conclusions: As most of these women with missed IUCD strings, IUCD was found to be in situ on ultrasound imaging; hence, these women need counselling regarding continuation of using IUCD. If required, removal can be done as an OPD procedure.
\end{abstract}

Keywords: Extrauterine IUCD, IUCD missed strings, IUCD displacement, IUCD expulsion, IUCD removal, Malposition of IUCD, Migration of IUCD, USG imaging

\section{INTRODUCTION}

Intrauterine Contraceptive Device (IUCD) is one of the most commonly used reversible method of contraception among married women of reproductive age. Worldwide, over 128 million women rely on intrauterine contraceptive devices for contraception. ${ }^{1}$ They provide very effective, safe and long-term protection against pregnancy, with prompt return to fertility upon removal; is convenient, does not require daily action on the part of the user, or repeated clinic visits for supplies. It has a failure rate of less than $1 \% .^{2}$ Its side effects are few and well tolerated. It can be inserted either as an interval procedure or after abortion or delivery. All IUCDs have threads which help in removal of the device, reassures its correct placement and retention. In India only $2 \%$ of married women of reproductive age use IUCDs. ${ }^{2}$ Despite the fact that the Government of India offers IUCD services free of cost, it still remains largely underutilized.

One of the main reasons that IUCD is underutilized in India is, that the advantages are understated, the disadvantages tend to be exaggerated and many myths and misconceptions are prevalent in the community and 
among the providers. One of the most important concerns is 'missing IUCD strings' which needs to be addressed. IUCD strings that are not visible at the external cervical os, are a commonly encountered problem, a detailed analysis of which is required. The objective of the present study was to analyse the prevalence, and clinical outcomes of missed IUCD strings in women using IUCD.

\section{METHODS}

This is an observational study conducted in Family planning OPD of Obstetrics and Gynecology Department of Hindu Rao Hospital and associated NDMC Medical College, Delhi, India from April 2017-September 2017.

\section{Inclusion criteria}

- The study population included IUCD users coming for routine checkup (follow-up/renewal/removal), with any complaints related to IUCD or gynecological complaints (pain abdomen /pelvis, menorrhagia, missed periods, vaginal discharge, urinary symptoms), or referred from other health center for missing IUCD strings or other IUCD related/gynae complaints and were found to be having missing threads.

A detailed demographic, menstrual and obstetric history was obtained. Details of IUCD were recorded which included type of IUCD insertion (Cu-T 380A or multiload), timing of insertion (interval / postpartum after vaginal delivery or intracesarean insertion), time since IUCD insertion and place of insertion (hospital or at health centers).

Present complaints if any, were asked i.e. pain in abdomen, menorrhagia, missed periods, vaginal discharge, urinary symptoms, expelled IUCD or IUCD threads. Desire for future pregnancy was also asked for. Per speculam examination to visualise IUCDs threads, any abnormal discharge and per vaginum examination for uterine position, size, mobility, any pelvic or adnexal tenderness, fullness or mass was carried out.

Non-invasive investigations like ultrasonogram pelvis was done to localise IUCD-whether intrauterine or not, any displacement or embedment in myometrium. If IUCD was found to be intra-uterine, without displacement, then woman was reassured and her complaints if any were addressed. If IUCD was not localised as intrauterine, X-ray pelvis and lower abdomen was done to see its presence or absence (expelled).

If a woman required removal for persistent gynae complaints or want of pregnancy or IUCD tenure completed; then simple outdoor interventions i.e., sounding of the uterus and gentle removal with artery forceps or IUCD hook was tried. If IUCD could not be removed by these simple OPD interventions, women were taken up in OT after due investigations. If on USG IUCD was found to be embedded then, attempt of removal was done in OT and not in OPD. In OT removal by dilatation and extraction by IUCD hook or dilatation and curettage/sucktion curettage or hyteroscopic removal was done. All data was recorded in a predesigned proforma.

\section{Statistical analysis}

Data was analyzed using SPSS version 20. Descriptive data were summarized as percentages. The Chi-square test was used to measure the strength of associations between variables. A p-value of $<0.05$ was considered as significant.

\section{RESULTS}

Out of 324 IUCD that were followed up during the study period, missed IUCD strings were found in 69 women $(22 \%)$ which were analysed. Significant more number of women were seen in age group of 25-35 years with parity 2-3.

Table 1: Demography and IUCD related data in women with missing IUCD threads $(\mathrm{N}=69)$.

\begin{tabular}{|c|c|c|c|}
\hline Parameter & $\mathbf{N}$ & $\%$ & P value* \\
\hline \multicolumn{3}{|l|}{ Age } & \multirow{4}{*}{0.001} \\
\hline$<25$ years & 25 & 36.23 & \\
\hline $25-35$ years & 35 & 50.72 & \\
\hline$>35$ years & 9 & 13.04 & \\
\hline \multicolumn{3}{|l|}{ Parity } & \multirow{4}{*}{$<0.001$} \\
\hline 1 & 23 & 33.34 & \\
\hline $2-3$ & 42 & 60.86 & \\
\hline$>3$ & 4 & 5.79 & \\
\hline Referred from other centers & 37 & 53.62 & \multirow[b]{2}{*}{0.547} \\
\hline $\begin{array}{l}\text { Came for follow up/with } \\
\text { complaints }\end{array}$ & 32 & 46.37 & \\
\hline \multicolumn{3}{|l|}{ Place of IUCD insertion } & \multirow{3}{*}{$<0.001$} \\
\hline Hospital & 49 & 71.01 & \\
\hline Health centers & 20 & 28.98 & \\
\hline \multicolumn{3}{|l|}{ Timing of IUCD insertion } & \multirow{5}{*}{$<0.001$} \\
\hline PPIUCD (NVD) & 10 & 14.49 & \\
\hline PPIUCD (LSCS) & 23 & 33.34 & \\
\hline PAIUCD & 2 & 2.89 & \\
\hline Interval IUCD & 34 & 49.27 & \\
\hline \multicolumn{3}{|l|}{ Type of IUCD } & \multirow{3}{*}{$<0.001$} \\
\hline $\mathrm{Cu} 380 \mathrm{~A}$ & 63 & 91.30 & \\
\hline Multiload & 6 & 8.69 & \\
\hline \multicolumn{3}{|l|}{ Time since IUCD insertion } & \multirow{4}{*}{0.296} \\
\hline$<1$ year & 25 & 36.23 & \\
\hline $1-5$ years & 27 & 39.13 & \\
\hline$>5$ years & 17 & 24.63 & \\
\hline
\end{tabular}

Significant difference was present among the various subgroups of age and parity ( $\mathrm{p}$ value 0.001). Significantly high number of women had got $\mathrm{Cu}-\mathrm{T} 380 \mathrm{~A}$ inserted at our institute as an interval procedure ( $\mathrm{p}$ value 
$<0.001)$. Time interval after insertion and diagnosing missing IUCD thread was found to be insignificant ( $\mathrm{p}$ value 0.296 ).

A mean interval of 37.67 months (3.13 years) was observed between insertion of IUCD and diagnosis of missing IUCD strings. Most of the women $(n=27)$ were found to have missing strings after 1-5 years of IUCD insertion.
When analysing women with missed IUCD strings who had undergone PPIUCD insertion and interval IUCD, it was found that significant more women with intracesarean IUCD insertion had missed threads ( $\mathrm{p}$ value < $0.001)$ at $<1$ year. Significant more women with interval insertion were found to have missed IUCD strings in the subgroup of 1-5 year and $>5$ years of insertion ( $\mathrm{p}$ value $<0.001$ and 0.002 respectively). (Table 2 ).

Table 2: Time since IUCD insertion in women with missed IUCD strings.

\begin{tabular}{|lllll|}
\hline Time $($ Years $)$ & PPIUCD LSCS & PPIUCD VD & Interval IUCD & p value \\
\hline$<1$ year $(\mathrm{n}=24)$ & $16(23.19 \%)$ & $5(7.24 \%)$ & $3(4.35 \%)$ & $<0.001$ \\
\hline $1-5$ years $(\mathrm{n}=26)$ & $6(8.69 \%)$ & $4(5.79 \%)$ & $16(23.19 \%)$ & $<0.001$ \\
\hline$>5$ years $(\mathrm{n}=17)$ & $1(1.44 \%)$ & $1(1.44 \%)$ & $15(21.74 \%)$ & 0.002 \\
\hline *Total $(\mathrm{N}=67)+2$ PAIUCD & $23(33.33 \%)$ & $10(14.49 \%)$ & $34(49.27 \%)$ & \\
\hline
\end{tabular}

*Two were PAIUCD (1 was inserted within 1 year, and one was inserted between 1-5 years)

Table 3: Complaints in women with missed IUCD strings.

\begin{tabular}{|c|c|c|c|c|}
\hline Complaints & $\begin{array}{l}\text { PPIUCD LSCS } \\
(n=23)(\%)\end{array}$ & $\begin{array}{l}\text { PPIUCD NVD } \\
(\mathbf{n}=10)(\%)\end{array}$ & Interval (n=34) & $\mathbf{P}$ value \\
\hline AUB $(n=15)$ & $8(11.59)$ & $4(5.79)$ & $3(4.34)$ & 0.024 \\
\hline AUB + pain $(n=03)$ & $1(1.44)$ & $0(0)$ & $2(2.89)$ & 0.796 \\
\hline Pain only $(n=8+1$ PAIUCD $*)$ & $3(4.34)$ & $0(0)$ & $5(7.24)$ & 0.443 \\
\hline Pain+ expulsion of thread $(n=0+1$ PAIUCD*) & - & - & - & NA \\
\hline Expulsion of thread $(\mathrm{n}=07)$ & $3(4.34)$ & $0(0)$ & $4(5.79)$ & 0.498 \\
\hline Asymptomatic $(n=34)$ & $8(11.59)$ & $6(8.69)$ & $20(28.98)$ & 0.167 \\
\hline Total $(\mathrm{N}=67+2$ PAIUCD $*=69)$ & $23(33.33)$ & $10(14.49)$ & $34(49.27)$ & \\
\hline
\end{tabular}

*PAIUCD $(\mathrm{n}=2)$ one had complaint of pain, other pain +expulsion of thread

Table 4: USG findings in women with missed IUCD strings.

\begin{tabular}{|c|c|c|c|c|}
\hline USG findings & PPIUCD LSCS & PPIUCD NVD & Interval & P value \\
\hline IUCD in situ ( $n=55+1$ PAIUCD*) & 19 & 9 & 27 & 0.742 \\
\hline IUCD displaced ( $\mathrm{n}=6+1 \mathrm{PAIUCD} *)$ & 1 & 1 & 4 & 0.625 \\
\hline Embedded in myometrium $(n=3)$ & 2 & 0 & 1 & 0.446 \\
\hline $\begin{array}{l}\text { IUCD not found/expelled }(n=3) \text {, Pregnancy }(n=1) \text {, } \\
\text { Confirmed with X-ray }(n=2)\end{array}$ & 1 & 0 & 2 & 0.731 \\
\hline Total: $(n=67+2$ PAIUCD $*=69)$ & 23 & 10 & 34 & \\
\hline
\end{tabular}

*2 cases of PAIUCD with missed IUCD tails, USG- one had IUCD in situ, other had displaced IUCD

Table 5. Reasons for removal of IUCD in women with missed IUCD strings.

\begin{tabular}{|lllll|}
\hline Reason for removal & Interval & PPIUCD & PPIUCD & P value \\
\hline Wanted conception & IUCD & LSCS & NVD & 0.182 \\
\hline IUCD tenure completed & 2 & 5 & 2 & - \\
\hline Displaced IUCD & 5 & 0 & 0 & 0.360 \\
\hline Embedded in myometrium & 4 & 1 & 1 & - \\
\hline Persistent AUB & 1 & 2 & 0 & 0.851 \\
\hline Persistent pelvic pain & 6 & 3 & 2 & 0.227 \\
\hline *Total reasons for removal =40 & 5 & 1 & 0 & 5 \\
No. of women who got IUCD was removed $(27+2 P A I U C D *)=29$ & 13 & 12 & 10 & 4 \\
\hline
\end{tabular}

*There were more than 1 reason for IUCD removal in some women. 2 PAIUCD were removed; 1 for persistent pain and other for persistent pain and displacement. 
$50.74 \%(n=34)$ of the women with missing IUCD strings were asymptomatic. Most of these women had an interval IUCD insertion $(n=20)$. AUB was the most common and significant complaint after intra-cesarean insertion of IUCD compared to insertion after normal vaginal delivery and interval IUCD insertion ( $p$ value 0.024 ). No significant difference was observed between other symptoms and type of IUCD insertion (Table3).

USG pelvis revealed intra-uterine IUCD in all except 3 women. In these 3 women who were asymptomatic IUCD was not visualised on USG. One had positive urine pregnancy test and underwent MTP. X-ray lower abdomen and pelvis confirmed absence of IUCD (expelled) in these 3 women. Displaced IUCD was detected in 6 women also in 1 woman who had postabortal IUCD insertion. IUCD was found to be embedded in myometrium in 3 women. No significant statistical difference was observed in type of IUCD insertion and IUCD imaged as in situ, displaced or embeded in myometrium on USG (Table 4). Out of 69 women with missed IUCD strings, removal was done in 29 women. There were more than 1 reason for IUCD removal. 9 women wanted pregnancy, 5 had tenure of IUCD completed, 7 women had displaced IUCD and 3 women had myometrial embedment.

11 women with persistent AUB and 8 women with persistent pelvic pain got IUCD removed. No significant difference was found in respect to reason for removal and type of IUCD insertion (Table 5). IUCD was removed by simple OPD procedure in $82.75 \%$ of cases by Spencerwell's artery forceps or IUD hook. Only $13.77 \%$ required removal as a minor OT procedure under IM sedation or short GA. Only 1 woman required hysteroscopic removal. Extra-uterine IUCD was not found in any women requiring laparoscopy or laparotomy (Table 6).

Table 6: Intervention required for removal of IUCD in women with missed IUCD strings.

\begin{tabular}{|lll|}
\hline $\begin{array}{l}\text { Intervention } \\
\text { OPD procedure, No aneasthesia, } \\
\text { artery forceps/ IUCD hook }\end{array}$ & $\mathbf{N}=29$ & $\%$ \\
\hline \begin{tabular}{l} 
OT procedure, IM sedation/short GA \\
\hline Dilatation and removal with hook
\end{tabular} & 32.75 \\
\hline Dilatation and curettage & 1 & 10.33 \\
\hline OT procedure/ GA & & \\
\hline Hysteroscopic removal & 1 & 3.44 \\
\hline Laparoscopy/laparotomy & Nil & 0.00 \\
\hline Total & 29 & 100 \\
\hline
\end{tabular}

Cause of missing IUCD was confirmed to be retracted IUCD threads in cervical canal in $18.84 \%(\mathrm{n}=13)$, broken or expelled threads in $23.18 \%(\mathrm{n}=16)$ and spontaneous expulsion of IUCD in $4.35 \%(n=3)$ women. No definite cause of missing IUCD strings could be elicited in the rest of $53.62 \%$ women $(n=37)$ as no intervention was done in these cases (Table 7).
Table 7: Cause/ diagnosis of missing IUCD strings.

\begin{tabular}{|lll|}
\hline Cause & N & $\%$ \\
\hline Retracted thread & 13 & 18.84 \\
\hline Detached/broken thread & 16 & 23.19 \\
\hline IUCD expulsion spontaneous & 3 & 4.35 \\
\hline Not known as no intervention was done & 37 & 53.62 \\
\hline Total & 69 & 100 \\
\hline
\end{tabular}

\section{DISCUSSION}

The use of IUDs has increased over the past 25 years and it is now the most widely used reversible, long acting contraceptive. Visualisation of strings of IUCD coming from the external cervical os during follow up examination ensures the women and the attending physician that IUCD is in place. Missing IUCD strings, i.e. IUCD strings that are not visible at the external cervical os, are a commonly encountered problem and needs to be addressed.

During our study period out of 324 women coming for follow up/ renewal/removal or with any complaints related to IUCD or gynaecological complaints or referred from other health centers for missing IUCD threads or some gynaeological complaints; missed IUCD strings were found in $69(22 \%)$ women.

Various other studies have reported an incidence between $4.5 \%-18.1 \%$ of missing IUCD strings. ${ }^{3}$ Marchi has reported missing strings in $5 \%$ of women. ${ }^{4}$ The incidence of missing strings was more $(22 \%)$ in our study, because many women were referred from nearby health centers and secondary level hospitals. In our study $49.27 \%$ $(n=34)$ women with IUCD threads were found to be asymptomatic, and $50.73 \%(n=35)$ had symptoms i.e. AUB with or without pain, pain with or without history of expelling threads. Similar observations have been made by Mishra $\mathrm{S}$ et al where more than $50 \%$ cases women with post-partum IUCD insertion with missing IUCD threads were found to be asymptomatic. ${ }^{5}$

No significant difference was found in respect to type of insertion (post-partum or interval) and symptoms except for AUB. AUB was the commonest symptom and was significantly more in post-partum than interval IUCD insertions ( $\mathrm{p}$ value 0.024$) .26 .08 \%(\mathrm{n}=18)$ women having missed IUCD threads had AUB, though only $15.9 \%$ $(n=11)$ women got it removed. Out of these 11 women, 5 did not respond to conservative treatment of AUB and in 6 women there were other associated reasons for IUCD removal i.e. displaced/embedded IUCD, wanting pregnancy and expiry of IUCD tenure. As per Population reports, an estimated $4 \%$ to $15 \%$ of women discontinued IUCD use within 1 year because of the menstrual symptoms. ${ }^{6}$

Pelvic pain was seen in $18.84 \%(n=13)$ women in our study, however only $11.59 \%(n=8)$ woman required removal for persistent pelvic pain. Only one woman was 
diagnosed as PID in our study. The remaining 7 had other associated reasons for removal i.e. AUB, displaced / embedded IUCD, wanting issue, tenure of IUCD completed.

Sonography is the optimal method for initial evaluation. It is important in assessing correct position and complications of IUCD including a low position, associated infection, myometrial migration, uterine perforation, intrauterine or extra-uterine pregnancy associated, and retention and fragmentation of the IUCD. ${ }^{7}$ On ultrasound, the IUCD is viewed as double bar sign and create shadowing. An USG performed immediately after attempting IUCD removal may be misleading, as focal hemorrhage can be highly echogenic and give a false impression of an IUCD in the uterus. The 3D TV US does not visualize an IUCD better than 2D TV USG. The 3D-reconstructed coronal image of the uterus can reliably diagnose $\mathrm{T}$-arm perforation into the adjacent myometrium, which could be missed on 2D TV US images. $^{8}$ In our study, all women had 2D USG performed.

In present study, IUCD was present in situ in $82.6 \%$ $(n=57)$ on USG imaging similar to study by Megha et al who found intrauterine IUCD in $81 \%$ women $(n=57)$ on USG imaging. ${ }^{9}$ Husemeyer reported that IUCD was found in situ in $87 \%$ women, not associated with pregnancy. ${ }^{10}$ These women were counselled to continue IUCD, unless removal for other symptoms /reasons was desired.

Displacement of IUCD (>3mm from its normal fundal position) was observed on USG in our study in $10.14 \%$ $(n=7)$ women on USG. The prevalence of displaced IUD reported by Ikechebelu was $3.6 \%$ in women with missing IUD strings. ${ }^{11}$ Braaten et al. studied retrospectively all ultrasound reports from a 5.5-year period and identified $10.4 \%$ displaced IUDs. ${ }^{12}$ Reduction of the incidence of IUCD displacement can be done by proper insertion technique, proper selection of cases and modifications of the IUCD (small sized IUCDs and frameless IUDs). ${ }^{13}$

Embedment as diagnosed on USG, refers to IUCD penetration into the endometrium or myometrium without extension through the serosa. It may occur up to some degree in up to $18 \%$ of females with an IUCD. ${ }^{14}$ Employing 3D ultrasound conducted in 413 women embedment of one or both arms 6 weeks after insertion of the LNG-IUS was found in more than $50 \%$ women. ${ }^{15}$ Embedment of IUCD was seen in $4.35 \%(n=3)$ in our study. Kathpalia et al in his study has also reported, four cases of IUCD buried under the endometrium. ${ }^{16}$ In a study by Megha et al embeded IUCD was reported in $61 \%$ women. ${ }^{9}$ Embedment is more common in females with smaller fundal endometrial diameters. ${ }^{17}$

USG as an initial investigation, if found to be inconclusive then abdominal plain films radiography should be done, including entire abdominal cavity, most dependent portion of the pelvis and most superior aspects of the upper quadrants of abdomen to prevent mistaking an intra-abdominal IUCD in the extremes of the abdominal cavity for an expelled IUCD. ${ }^{3}$ In our study IUCD was not localized on USG in 3 women. One had positive urine pregnancy test and underwent MTP. In these 3 women X-ray abdomen and pelvis confirmed spontaneous expulsion of IUCD. Unnoticed expulsion may lead to missed periods and pregnancy and is reported in between $<5 \%-6.6 \%$. of cases with missing strings. ${ }^{13,18}$ An expulsion rate $2-10 \%$ in 1 st year of use, has been quoted. ${ }^{19}$ In our study spontaneous expulsion of IUCD in women with missed IUCD threads was found to be less $(4.35 \%, n=3)$, as our study population included the interval insertions also. Insertion early in the menstrual cycle may increase the likelihood of expulsion. ${ }^{20}$ Other risk factors include nulliparity, menorrhagia, and immediate postpartum insertion, after $2^{\text {nd }}$ trimester abortion. ${ }^{21-23}$ Patients with severe anatomic distortion of the uterine cavity (eg, a bicornuate uterus or large submucosal fibroids) may be at higher risk for IUD expulsion or difficulty with placement. ${ }^{24}$

Occurrence of pregnancy in a woman using IUCD should raise the suspicion of misplaced device. ${ }^{25}$ Pregnancy with an IUCD is associated with adverse outcomes for the mother and fetus. When displaced into the uterine cavity with co-existing pregnancy, IUCD can be left in situ or carefully removed to avoid interference with the ongoing pregnancy. We did not observe any woman with pregnancy and IUCD in situ. One woman with pregnancy had her IUCD already expelled. CT/ MR imaging is not required routinely for evaluating woman with missed IUCD thread. ${ }^{14,26}$ However, CT is the best modality for the evaluation of complications associated with intraabdominal IUCDs, such as visceral perforation, abscess formation, and bowel obstruction. ${ }^{14,27}$ None of the women in our study required CT/MR imaging.

Removal of IUCD in our study was required in 29 women out of $69(42 \%)$ women with missed IUCD strings. Reasons for removal were: 9 women desired pregnancy, 5 had tenure of IUCD completed, 11 had persistent AUB 8 had persistent pelvic pain (including 2 with PAIUCD) and 7 had intra-uterine displacement of IUCD (including 1 with PAIUCD) and 3 had embedded IUCD. It is recommended to remove all low-lying (>3 $\mathrm{mm}$ from the fundus) copper IUCDs as adequate protection cannot be guaranteed. ${ }^{13}$ Also, all misplaced including embedded, extra-uterine IUCDs require removal.

Extra-uterine perforation/ migration of IUCD is rare. Case reports by various authors have reported migration/perforation into the abdominal or pelvic cavity, colon, appendix, POD, broad ligament, bladder, colon, uterine tube or uterine wall, ovary, rectum/anus, ileum. ${ }^{28-}$ ${ }^{31}$ Perforation should be considered in difficult insertions, retroverted uterus, previous scar, nulliparous women who present with pain. "Primary" perforations occur at the 
time of IUD insertion, and "secondary," or delayed perforations are usually assumed to be caused by reactive uterine contractions. ${ }^{32} \mathrm{We}$ did not come across any women having perforation/ migration of IUCD in our study.

In present study IUCD removal was easily done in 24 out of the $29(82.7 \%)$ women, as a simple outdoor procedure by artery forceps or IUCD hook without anaesthesia. Women with embedded IUCD in myometrium as diagnosed by USG imaging $(n=3)$, attempt for removal was not made in OPD. In 2 other cases attempt for removal in OPD with artery forceps was not successful; thus, in these 5 women removal of IUCD was done in OT under IM sedation or short GA. Dilatation of cervix and removal by IUCD hook/curettage was done in 4 women. Only one woman required hysteroscopic removal. None of the woman required laparotomy or laparoscopic removal.

These observations are similar to Kathpalia et al where most of the IUCDs could be removed by artery forceps in OPD and only one underwent hysterosopic removal; none of the women underwent laparotomy or laparoscopic removal. $^{16}$ In a study by Megha et al hysteroscopic removal was done in $61 \%$, removal by artery forceps was done in $20 \%$, laparoscopic removal and laparotomy in $6 \%$ and $2 \%$ respectively. ${ }^{9}$ Retrieval loop alone was used in management of $64.29 \%$ women with missed IUCD thread by Jimoh et al. ${ }^{33}$ Liang Lin could remove all IUCDs except one as an OPD procedure and concluded in his study that lost IUDs either with or without strings can be effectively and safely retrieved in the office-based setting without analgesia or anesthesia. ${ }^{34}$ Swenson $\mathrm{C}$ in a series of 29 cases of IUCD with strings not visible, removed all IUCDs as in office procedure. ${ }^{35}$

Thus, women with missing IUCD strings can be managed in the office or clinic with relatively simple techniques of removal if removal is indicated or the woman desires so.

No cause for the missing IUCD strings could be assigned to $53.62 \%(\mathrm{n}=37)$ women as no intervention was required in these. These women had IUCD normally positioned on ultrasound imaging. Probably retracted thread in the cervical canal or uterine cavity might have been the cause for the missing IUCD strings. None of the women with missing threads had pregnancy or extra-uterine displacement (misplacement) /perforation of IUCD in our study. Kathpalia et al, did not observe any case of perforation as in our study. ${ }^{16}$

Commonest cause of missed IUCD strings in our study was found to be broken, detached or severed strings seen in $23.18 \%(n=16)$ women. Many of the broken/severed strings were diagnosed after IUCD removal. Retracted strings were seen in $18.84 \% \quad(n=13)$ women and expulsion of IUCD in $4.35 \%(n=3)$. Marchi, have reported the most common reason to be retracted strings into cervix or uterine cavity with $98 \%$ found normally positioned, $1.2 \%$ expelled, $0.7 \%$ uterine perforation. ${ }^{4}$ In a study of 100 patients with missing IUD strings by Millen A; 4 were pregnant and 17 had unnoticed expulsions (4 pregnancies); 9 devices were in the peritoneal cavity and one had perforated the cervix. IUCD was in the uterine cavity in the majority of these cases. ${ }^{36}$

Therefore, all clients should be educated about the definite benefits of the device; side effects and complications which can occur, but their probability is very remote.

\section{CONCLUSION}

Missing IUCD strings is emerging as a potential deterrent for its use. Mere absent IUCD string on per speculum examination is not the indication for IUCD removal because in most of the cases IUCD was found to be in situ on ultrasound imaging. Hence, these women need counselling regarding continuation of using IUCD. Advice for IUCD removal is being rampantly given by health care service provider in such cases, which should be curtailed.

IUCD related complication like bleeding and pelvic pain should be investigated for other causes and to be medically managed first. Not all gynae symptoms are IUCD related and only few require intervention. Missed IUCD should not be considered as problem if USG reveals in situ placement. Important message is 'do not panic'. It is safe and effective and should be widely promoted.

Funding: No funding sources

Conflict of interest: None declared

Ethical approval: The study was approved by the Institutional Ethics Committee

\section{REFERENCES}

1. Ezegwui HU, Ikeako LC, Egbuji C. Missing intrauterine contraceptive device amongst clients in Enugu Nigeria. Niger J Surg. 2011;17(2):90-3.

2. IUCD reference manual for medical officers and nursing personnel, September 2013, Family planning division, Ministry of Health and Family Welfare, Government of India. Available at: https://nrhm.gujarat.gov.in/images/pdf/IUCD_Referenc e_Manual_Nursing_Personnel.pdf.

3. Prabhakaran S, Chuang A. In-office retrieval of intrauterine contraceptive devices with missing strings. Contracep. 2011;83(2):102-6.

4. Marchi NM, Castro S, Hidalgo MM, Hidalgo C, Monteiro DC, Villarroeal $M$ et al Management of missing strings in users of intrauterine contraceptives. Contracep. 2012;86(4):354-8.

5. Mishra S. Tail of the tails. The missing post-partum IUCD strings. J Obstet Gynaecol India. 2017; $23 ; 67(3): 202-7$. 
6. Population reports, IUD. The Johns Hopkin University, Baltimore, USA. March 1988. Available at: https://www.k4health.org/sites/default/files/047974.pdf.

7. Peri N, Graham D, Levine D. Imaging of intrauterine contraceptive devices. J Ultrasound Med. 2007; 26(10):1389-401.

8. Kerr NK, Dunham R, Wolstenhulme S, Wilson J. Comparison of two- and three-dimensional transvaginal ultrasound in the visualization of intrauterine devices. Ultrasound. 2014;22(3):141-7.

9. Gupta M, Jain G. Misplaced IUCD: Challenges and Management. People's J Sci Res. 2016;9(2):14-17.

10. Husemeyer RP. Missing intra-uterine contraceptive device threads- clinical significance and management. J Obstet Gynecol. 1982;2 (3):189-94.

11. Ikechebelu JI, Onwusulu DN. Missing IUD string: prevalence, diagnosis and retrieval in Nnewi, Nigeria. Niger J Med. 2009;18(3):303-5.

12. Braaten K, Goldberg AB. Malpositioned IUDs: When you should intervene (and when you should not). OBG Management. 2012; 24(8):39-46.

13. Wildemeersch D, Hasskamp T, Goldstuck ND. Malposition and displacement of intrauterine devicesdiagnosis, management and prevention. Clin Obstet Gynecol Reprod Med.2016;2(3):183-8.

14. Boortz HE, Margolis DJA, Ragavendra N, Patel MK, Kadell BM. Migration of Intrauterine Devices: Radiologic Findings and Implications for Patient Care. Radio Graphics. 2012;32(2):335-52.

15. Van Schoubroeck D, Van den Bosch T, Ameye L, Veldman J, Hindryckx A, Werbrouck E, et al. Pain and bleeding pattern related to levonorgestrel intrauterine system (LNG-IUS) insertion. Eur J Obstet Gynecol Reprod Biol. 2013;171(1):154-6.

16. Kathpalia SK, Singh MK, Grewal DS. Nonpalpable intrauterine device threads: Is it a cause for worry? Med J Armed Forces India. 2017;73(1):85-7.

17. Shipp TD, Bromley B, Benacerraf BR. The width of the uterine cavity is narrower in patients with an embedded intrauterine device (IUD) compared to a normally positioned IUD. J Ultrasound Med. 2010; 29(10):14536.

18. Tomar B, Saini V, Gupta M. Post-partum intrauterine contraceptive device: acceptability and safety. Int $\mathrm{J}$ Reprod Contracept Obstet and Gynecol. 2018;7(5):2011-7.

19. American College of Obstetricians and Gyneologists. Long acting reversible contraception: Implants and intrauterine devices. Practice Bulletin No. 121. Obstet Gynecol .2011;118(1):184-96.

20. White MK, Ory HW, Rooks JB, Rochat RW. Intrauterine device termination rates and the menstrual cycle day of insertion. Obstet Gyecol. 1980;55(2):2204.

21. Zhang J, Feldblum PJ, Chi IC, Farr MG. Risk factors for copper T IUD expulsion: an epidemiological analysis. Contracep. 1992;46(5):427-33.

22. Müller L, Letti Müller AL, Lopez Ramos JG, MartinsCosta SH, Palma Dias RS, Valério EG, et al.
Transvaginal ultrasonographic assessment of the expulsion rate of intrauterine devices inserted in the immediate postpartum period: a pilot study. Contracep. 2005;72(3):192-5

23. WHO Medical eligibility criteria for contraceptive use. $5^{\text {th }}$ Ed; Available at: http://apps.who.int/iris/bitstream/handle/10665/181468/ 9789241549158_eng.pdf;jsessionid=DE372572D52D3 B2F8FDA13C619563B0C? sequence $=1$.

24. Creinin MD. Intrauterine Devices: Separating Fact From Fallacy. Medsape. 1996;1(1):4.

25. Goswami D, Ravi AK, Sharma A. Missing IUCD Strings: Role of Imaging in Locating the Misplaced Device. J Clin Diagn Res. 2017;11(4): QJ01-2.

26. Zieman M, Kanal E. Copper T. 380A IUD and magnetic resonance imaging. Contracep. 2007; 75(2):93-5.

27. Hederstrom E, Ahlgren and Salminen H. Computed Tomography for Localization Of Intra-abdominally Dislocated Intrauterine Devices. Actta Radiologica. 1989;30(5):531-3.

28. Darlong L.M, Panad S, Topno N, Hajong R. Colonoscopic retrieval of migrated Copper-T. J Minim Access Surg. 2009;5(2):40-2.

29. Johri Vand Vyas KC. Misplaced Intrauterine Contraceptive Devices: Common Errors; Uncommon Complications. J Clin Diagn Res. 2013;7(5):905-7.

30. Sankareswari R, Indira, Geetha K, Vani S. Misplaced and Migrated IUCD: A case report. J Evol Med Dental Sci. 2014;3(25):7031-5.

31. Varun N, Nigam A, Gupta N. Misplaced IUCD: A Case Report. Int J Reprod Contracept Obstet Gynecol. 2017;6(11):5155-7.

32. Grimaldi L, De Giorgio F, Andreotta P, D'alessio MC, Piscicelli C, Pascali VL. Medicolegal aspects of an unusual uterine perforation with multiload-Cu375R. Am J Forensic Med Pathol. 2005;26(4):365-6.

33. Jimoh AAG, Balogun RO. Missing IUD strings: diagnosis and management at Ilorin. Niger $\mathbf{J}$ Med. 2004;13(2):118-23.

34. Bao-Liang L, Lida M, SuzukI T, Yabuno A, SeonHyeKim, Iwata $\mathrm{S}$ et al. Office management of lost intrauterine devices either with or without strings. Gynecology and minimally invasive therapy. 2014; $3(1): 15-8$.

35. Swenson C, Royer PA, Turok DK, Jacobson JC, Amaral G, Sanders JN. et al. Removal of LNG IUD when strings are not visible: a case series. Contracep. 2014; 90(3):288-90.

36. Millen A, Austin F, Bernstein GS., Analysis of 100 cases of missing IUD strings. Contracep. 1978;18(5): 485-95.

Cite this article as: Verma U, Gupta M, Saini V. Missing IUCD strings: an analysis. Int J Reprod Contracept Obstet Gynecol 2018;7:4061-7. 